\title{
Familial Keloid in Indian Scenario: Case Report and Review of Literature
}

\author{
Snigdha Goyal' ${ }^{1}$, Isha Saini'2, Sunder Goyal ${ }^{3}$ \\ ${ }^{1}$ Department of Pathology, Dr. RML Postgraduate Institute of Medical Sciences, New Delhi, India \\ ${ }^{2}$ Kalpna Chawla Medical College, Karnal, Haryana, India \\ ${ }^{3}$ Department of Surgery, Kaplna Chawla Medical College, Karnal, Haryana, India \\ Email: goyal.sunder@yahoo.in
}

Received 28 June 2015; accepted 14 July 2015; published 21 July 2015

Copyright (C) 2015 by authors and OALib.

This work is licensed under the Creative Commons Attribution International License (CC BY).

http://creativecommons.org/licenses/by/4.0/

(c) (i) Open Access

\begin{abstract}
Keloid disease is a fibro proliferative skin tumor and occurs after a skin trauma in genetically vulnerable individuals. Etiology of keloid is unclear. Causative factors for keloid are increased familial aggregation, a higher prevalence in certain races, parallelism in identical twins, and alteration in gene expression. It appears that the surroundings activate the disease in genetically susceptible individuals. Several genes are considered responsible for keloid disease, but no single gene mutation has thus far been found to be responsible. Therefore, we should apply a combination of methods such as association, gene-gene interaction, epigenetics, linkage, gene expression, and protein analysis to find out the keloid etiology. Incidence of familial keloid is common in Africans but is uncommon in Indian population. It may be due to autosomal dominant or autosomal recessive inheritance.
\end{abstract}

\section{Keywords}

Familial Keloid, Autosomal Dominant, Autosomal Recessive

Subject Areas: Surgery \& Surgical Specialties

\section{Introduction}

Keloids are benign hyper proliferative reaction of dermal fibroblasts demonstrated by the excessive deposition of extracellular matrix components, especially collagen, fibronectin, elastin, proteoglycans, and growth factors such as transforming growth factor (TGF) $\beta$. Modification in growth factors, excessive collagen, genetic and immunological factors contribute in keloid formation. Risk factors for keloid formation in susceptible persons are trauma, foreign-body reactions, infections, and endocrine dysfunctions. Keloid disease affects both sexes

\footnotetext{
${ }^{*}$ Corresponding author.
} 
equally [1]. Worldwide keloid distribution varies by geographic heritage from $0.09 \%$ in Great Britain to $16 \%$ in Congo [2]. Darker-skinned individuals and those of African descent are mostly affected [3]. Even total African village population can be affected with familial keloid but in Indian population it is uncommon to find a case of familial keloid. Keloid scar on exposed body parts affects emotionally as well as cosmetically and thus impairs physical and psychological quality of life. Age of keloids and the fraction of affected individuals in a family, are variable but are more prevalent between the ages of 10 and 30. Certain families manifest keloids in distinct location. We report a case of familial keloid in Indian patient which affected the upper chest of family members.

\section{Case Report}

A 35 years lady presented with flat keloid lesion of upper chest for the last one year. There was history of itching in the swelling. She complained of similar disease in her daughter and son. She was diagnosed as having keloid as this developed after minor scratch over upper chest. On examination, there was a flat $3.5 \times 2 \mathrm{cms}$, reddish brown colored lesion with irregular and raised margins. Daughter and son also had similar lesion on upper chest without any history of trauma (Figure $1 \&$ Figure 2). Mother was treated with intralesional steroids.

\section{Discussion}

Keloids and hypertrophic scars are different clinically and pathologically. Keloid may appear spontaneously or following a trauma. It expands beyond the margin of the wound, and persists and may expand for numbers of years. Histologically, keloids are characterized by a greatly expanded dermis occupied by large, hyalinized collagens fibers that are strongly eosinophilic. Keloids show dermal nodules with less distinct borders [4].

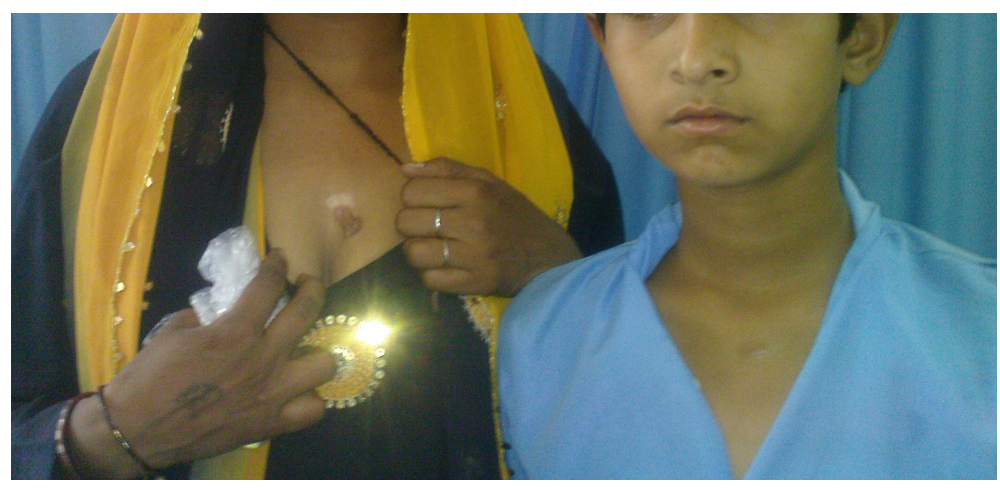

Figure 1. Showing mother and son with keloid on chest wall.

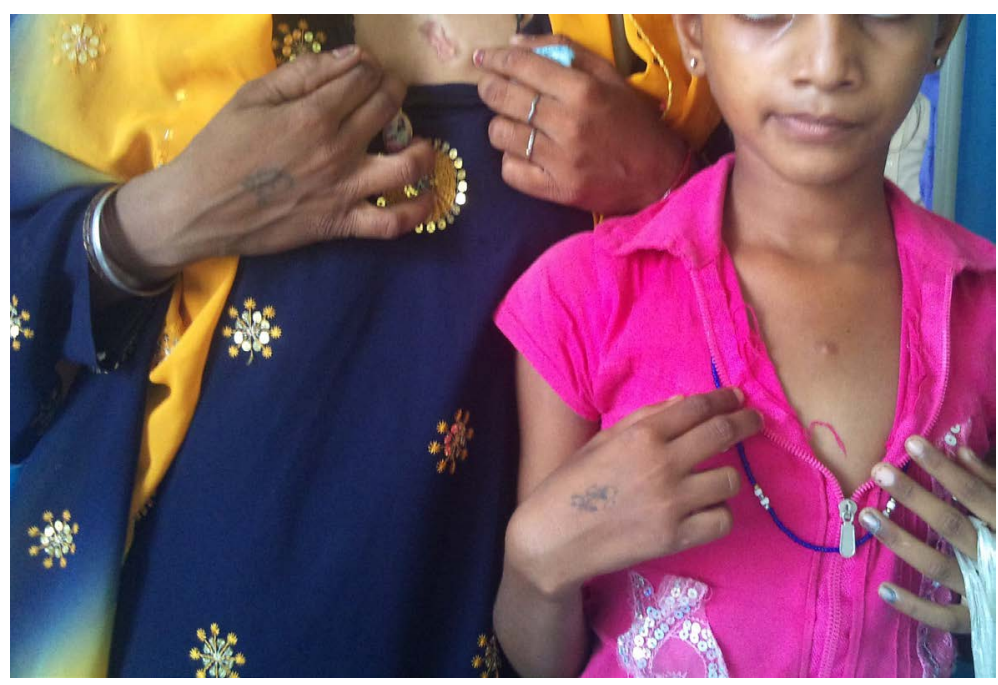

Figure 2. Showing mother and daughter with keloid on chest wall. 
Pathogenesis of Keloid Disease: Numerous theories have been proposed for the pathogenesis of keloids. Ethnicity affects the prevalence of keloid disease. Patients with darker skin, however, have a higher prevalencethan those with lighter pigmentation. Both autosomal dominant with incomplete penetrance as well as autosomal recessive modes of inheritance is found among families with keloid disease.

Several Mendelian disorders can be associated with keloids as part of their clinical features and keloids can develop in person with a connective-tissue disorder.

Keloids are enriched in growth factors and extracellular matrix (ECM) molecules and ECM molecules play an important role in skin structure; therefore, disruption of the ECM could be responsible for abnormal scar tissue formation. Keloid tissue is characterized by the accumulation of ECM, especially collagen. Keloid-derived fibroblast cells exhibit high expression of TGF $\beta 1$ and TGF $\beta 2$ and thus results in excessive collagen synthesis. TGF $\beta 3$ stimulates collagen synthesis via TGF $\beta 1$ and TGF $\beta 2$. TGF $\beta 1$ is expressed by neovascular endothelial cells in the primary stages of fibrosis in keloid tissue, which therefore stimulate the expression of type I and VI collagens at a high level. TGF $\beta 1$ is a key factor in keloid development and regulates the expression of multiple downstream genes. Exogenous TGF $\beta 1$ up regulates the expression of platelet derived growth factor (PDGF) $\alpha$ receptor in keloid-derived fibroblast cells but not in non-keloid-derived fibroblast cells. It has also been shown that TGF $\beta$ stimulates the expression of vascular endothelial growth factor (VEGF) in keloid fibroblasts as well. SMAD2 and SMAD3 play a critical role in TGF $\beta$-induced fibrosis in the formation of keloids [1].

No study has yet found any association between TGF $\beta$ family members and keloid disease in Caucasian populations in spite of strong evidence from expression studies. Polymorphisms in TGFB1, TGFB2, and TGFBR1 were not linked with keloids or hypertrophic scars [5].

Familial keloids manifest autosomal dominant inheritance. Bloom reported 31 mostly European keloid pedigrees, including one of African origin [6]. Marnerose et al. reported 14 American keloid pedigrees and concluded that the pattern of inheritance observed in these families is consistent with an autosomal dominant mode with incomplete clinical penetrance and variable expression [7] and Chen et al. reported 6 Han Chinese pedigrees [8]. Omo-Dare et al. analyzed 34 pedigrees in Nigeria and concluded that the data indicated recessive inheritance [9].

Treatment of keloid lesion depends upon many factors like, size of lesion, location, depth of lesion, age of patient, and past response to treatment. Surgical excision, radiation, pressure therapy, cryotherapy, intralesional injection of corticosteroids, interferon and fluorouracil, topical silicone and other dressings, and pulse-dye laser treatment have been found to induce some degree of regression. Other therapies including intralesional calcium channel blockers, bleomycin, cyclosporine, topical retinoic acid and imiquimod have shown promise in the treatment of keloids. Yet there is no universally accepted treatment protocol despite the broad range of treatment modalities. In most instances these therapies are used as an adjuvant to surgical excision [10]. As post-surgery keloid are common in these families, prophylactic measures should be taken from beginning including preoperative counseling.

\section{Conclusion}

Familial keloids appear to be most commonly manifested autosomal dominant or semidominant inheritance, and there may be familial patterns of keloid distribution. As post-surgery keloid is common in these families, prophylactic measures should be taken during surgery along with preoperative counseling.

\section{References}

[1] Halim, A.S., Emami, A., Salahshourifar, I. and Kannan, T.P. (2012) Keloid Scarring: Understanding the Genetic Basis, Advances, and Prospects. Archives of Plastic Surgery, 39, 184-189. http://dx.doi.org/10.5999/aps.2012.39.3.184

[2] Kelly, A.P. (1988) Keloids. Dermatologic Clinics, 6, 413-424.

[3] Slemp, A.E. and Kirschner, R.E. (2006) Keloids and Scars: A Review of Keloids and Scars, Their Pathogenesis, Risk Factors, and Management. Current Opinion in Pediatrics, 18, 396-402. http://dx.doi.org/10.1097/01.mop.0000236389.41462.ef

[4] Clark, J.A., Turner, M.L., Howard, L., Stanescu, H., Kleta, R. and Kopp, J.B. (2009) Description of Familial Keloids in Five Pedigrees: Evidence for Autosomal Dominant Inheritance and Phenotypic Heterogeneity. BMC Dermatology, 9, 8. http://dx.doi.org/10.1186/1471-5945-9-8

Xai, W., Phan, T.T., Lim, I.J., Longaker, M.T. and Yang, G.P. (2006) Differential Transcriptional Responses of Keloid and Normal Keratinocytes to Serum Stimulation. Journal of Surgical Research, 135, 156-163. 
http://dx.doi.org/10.1016/j.jss.2006.01.031

[5] Bayat, A., Bock, O., Mrowietz, U., Ollier, W.E. and Ferguson, M.W. (2004) Genetic Susceptibility to Keloid Disease: Transforming Growth Factor Beta Receptor Gene Polymorphisms Are Not Associated with Keloid Disease. Experimental Dermatology, 13, 120-124. http://dx.doi.org/10.1111/j.0906-6705.2004.00165.x

[6] Bloom, D. (1956) Heredity of Keloids; Review of Literature and Report of a Family with Multiple Keloids in Five Generations. New York State Journal of Medicine, 56, 511-519.

[7] Marneros, A.G., Norris, J.E., Olsen, B.R. and Reichenberger, E. (2001) Clinical Genetics of Familial Keloids. Archives of Dermatology, 137, 1429-1434. http://dx.doi.org/10.1001/archderm.137.11.1429

[8] Chen, Y., Gao, J.H., Lui, X.J., Yan, X. and Song, M. (2006) Characteristics of Occurrence for Han Chinese Familial Keloids. Burns, 32, 1052-1059. http://dx.doi.org/10.1016/j.burns.2006.04.014

[9] Omo-Dare, P. (1975) Genetic Studies on Keloid. Journal of the National Medical Association, 67, 428-432.

[10] Jones, K., Fuller, C.D., Luh, J.Y., Childs, C.C., Miller, A., Tolcher, A.N., Herman, S. and Thomas, C.R. (2006) Case Report and Summary of Literature: Giant Perineal Keloids Treated with Post-Excisional Radiotherapy. BMC Dermatology, 6, 7. http://dx.doi.org/10.1186/1471-5945-6-7 